\title{
Impact and factors associated with nighttime and early morning symptoms among patients with chronic obstructive pulmonary disease
}

This article was published in the following Dove Press journal:

International Journal of COPD

17 March 2015

Number of times this article has been viewed

\author{
Judith J Stephenson' \\ Qian Cai' \\ Michelle Mocarski \\ Hiangkiat Tan' \\ Jalpa A Doshi ${ }^{3}$ \\ Sean D Sullivan ${ }^{4}$
}

'HealthCore, Inc., Wilmington, DE, USA; ${ }^{2}$ Forest Research Institute, Inc., an affiliate of Actavis, Inc., Jersey City, NJ, USA; ${ }^{3}$ University of Pennsylvania, Philadelphia, PA, USA; ${ }^{4}$ University of Washington, Seattle, WA, USA

Correspondence: Judith J Stephenson HealthCore, Inc., 800 Delaware Avenue, 5th Floor, Wilmington, DE I980I, USA Tel +l 3022302142

Email jstephenson@healthcore.com

\begin{abstract}
Patients with chronic obstructive pulmonary disease (COPD) exhibit poor sleep quality and consider morning as the worst time of day for their symptoms. While work has been done to characterize nighttime (NT) and early morning (EM) symptoms in various populations, the impact and factors associated with NT/EM symptoms among patients with COPD in the United States is not well understood. Commercially insured patients aged $\geq 40$ years with one or more medical claim for COPD and one or more pharmacy claim for COPD maintenance medication were identified from the HealthCore Integrated Research Database between September 1, 2010 and August 31, 2011. Consenting respondents were asked whether they had COPD symptoms on at least three nights or at least three mornings during the past week. Respondents were then either assigned to one of three symptom groups to complete the survey or excluded if their predefined group quota limit had been met. Survey completers completed the survey with questions about COPD symptoms and other commonly used patient-reported outcome measures. Respondents with NT/EM symptoms were asked about the frequency, severity, and impact of the symptoms on sleep, morning activities, and anxiety levels. Among respondents with symptoms, $73.1 \%$ of respondents with NT symptoms $(\mathrm{N}=376)$ and $83 \%$ of respondents with EM symptoms $(\mathrm{N}=506)$ experienced at least three distinct types of symptoms over the past week, with cough being the most frequently reported symptom. Approximately half of respondents with NT or EM symptoms perceived their symptoms as moderate to very severe, with a majority reporting their symptoms affected their NT sleep and morning activities, and more than half felt anxious due to their symptoms. Multinomial logistic regression showed COPD patients with both or either NT/EM symptoms were associated with poorer health status compared to those without. Improved disease management may reduce NT/EM symptoms and improve health status in patients with COPD.
\end{abstract}

Keywords: chronic airflow obstruction, chronic limitation of activity, quality of life, sleep

\section{Introduction}

Chronic obstructive pulmonary disease (COPD) is a common, preventable, and treatable pulmonary condition characterized by persistent airflow limitation that is not fully reversible. ${ }^{1}$ In the United States, approximately 24 million American adults may have airflow limitations consistent with COPD ${ }^{2}$ with about half being undiagnosed ${ }^{3,4}$ COPD has risen to the third leading cause of death in the US, accounting for approximately 138,000 deaths in $2010 .^{5,6}$ COPD has also risen to the third cause of death worldwide from 1990 to 2010, although the change in numbers of deaths declined by $7 \%$.

The most common symptoms of COPD include dyspnea, chronic cough, sputum production, wheezing, and chest tightness. ${ }^{8}$ COPD symptoms are particularly disruptive during the nighttime (NT) and/or early morning (EM), contributing to sleep 
disturbance, limited morning activities, and poor health status. ${ }^{9-13}$ Epidemiological data indicate that more than $75 \%$ of patients with COPD may experience nocturnal symptoms. ${ }^{9}$ NT symptoms are often underreported, are not considered in the clinical management of COPD, and are likely to negatively impact sleep quality and impair health status. ${ }^{9}$ Similar to effects of NT symptoms, Kessler et $\mathrm{al}^{10}$ found that morning symptoms were also a burden to patients with COPD, with the majority reporting troublesome phlegm and cough upon waking or in the EM. Moreover, the morning has been reported as the worst time of a day by COPD patients, especially among those with severe COPD, as COPD symptoms in the morning have been shown to limit patients' ability to perform morning activities. ${ }^{10,11,13}$ Patients with COPD expect their treatment to provide fast symptom relief, greater mobility, and improvement in morning activities, ${ }^{13}$ however, such patient expectations have not been emphasized in clinical management guidelines. ${ }^{14}$ In an effort to improve COPD management, the present study determined the type, frequency, severity, and duration of NT/EM symptoms; assessed the impact of these symptoms on sleep, morning activities, and anxiety levels; and investigated factors associated with the presence of these symptoms among commercially insured COPD patients in the US.

\section{Methods}

\section{Study design}

The study consisted of a cross-sectional survey of patients with COPD. The patient sample was identified using medical and pharmacy claims from the HealthCore Integrated Research Database, a large administrative claims database with claims from 14 geographically dispersed US health plans.

Patients were included if they met the following criteria at the time the patient sample list was determined: 1) at least one medical claim with an International Classification of Diseases, 9th Revision, Clinical Modification (ICD-9-CM) diagnosis code for COPD (ICD-9-CM 491.xx, 492.xx, or 496.xx) and at least one pharmacy claim for a COPD maintenance medication (ie, inhaled corticosteroids, short acting $\beta_{2}$ adrenergic agonist, long acting $\beta_{2}$ adrenergic agonist, short acting anticholinergics, methylxanthines, phosphodiesterase-4 inhibitors) between September 1, 2010 and August 31, 2011; 2) at least 40 years of age; 3 ) continuous health plan eligibility between September 1, 2010 and August 31, 2011; 4) commercially insured, active health plan member; and 5) satisfied all other HealthCore survey eligibility criteria (eg, no missing contact information, and not on any do-not-call lists). Patients with medical claims for other lung diseases (eg, lung cancer, cystic fibrosis, active tuberculosis, interstitial lung disease, $\alpha 1$-antitrypsin deficiency) or HIV were excluded.

\section{Survey recruitment}

Eligible patients were invited to participate in the study via a prenotification letter, which included telephone numbers that patients could call to proactively opt into or opt out of the study. Patients who did not respond to the prenotification letter were contacted by telephone, and those patients who gave verbal consent were asked whether they had COPD symptoms on at least three nights (ie, between the time of going to bed and the time of getting up to start a day) or at least three mornings (ie, between the time of getting out of bed and approximately $11 \mathrm{am}$ ) during the past week. Based on their responses, patients were either assigned to one of three symptom groups (both NT and EM symptoms; NT symptoms only or EM symptoms only; or no symptoms) and completed the full survey, or excluded if their predefined group quota limit had been met. The targeted number of completed surveys was 750. Survey completers were administered a 30-minute survey with questions about COPD symptoms, clinical and demographic information, and other commonly used patientreported outcome measures. The survey recruitment began in February 2012 and ended in April 2012.

A central Institutional Review Board reviewed and approved all survey-related materials (survey protocol, prenotification letter, telephone recruiting script, and patient survey) and all patients provided verbal consent before responding to questions. Patient-level data were handled in compliance with the Health Insurance Portability and Accountability Act regulations. Any information that could uniquely identify individual patients was removed from the survey data prior to analysis and reporting.

\section{Survey measures}

\section{Assessment of NT and EM symptoms}

Respondents with NT and/or EM symptoms were asked about the specific symptoms they experienced at night or in the EM, respectively. Respondents with symptoms were further asked about the number of nights/mornings during the past week that they had experienced these symptoms, the severity of their symptoms, and the impact of their symptoms on their sleep or EM activities. Finally, respondents were asked how long they had experienced their symptoms.

\section{Demographic and clinical characteristics}

Demographic and patient-reported clinical information was collected from all respondents. Clinical information included 
age at COPD diagnosis; duration of COPD; current smoking status; height and body weight; the use of home oxygen, oral steroids, and/or sleep medications during the week prior to the survey; and the number of COPD exacerbations in the past 12 months.

\section{Patient-reported outcome measures}

The modified Medical Research Council (mMRC) dyspnea scale consists of a single question describing the degree of breathlessness associated with various physical activities, such as walking or dressing, ${ }^{15}$ and was used as a proxy measure of COPD severity, with higher grades indicating more-severe dyspnea. ${ }^{16}$ The COPD Assessment Test is an eight-item scale used to assess the impact of COPD on health status, ${ }^{17}$ with higher scores indicating a greater impact of COPD on health status. The Morisky Medication Adherence Scale consists of eight items and assessed adherence in respondents currently taking COPD medications, with scores less than 6 indicating low adherence, scores of 6 to $<8$ indicating moderate adherence, and scores of 8 indicating high adherence. ${ }^{18}$

\section{Statistical analyses}

Descriptive statistics were used to summarize the data, including frequencies and percentages for categorical variables and means and standard deviations for continuous variables. Demographic and clinical characteristics were analyzed using chi-square or Fisher's exact test for categorical variables, and analysis of variance for continuous variables. Multinomial logistic regression was used to identify factors associated with NT and/or EM symptoms using patients without symptoms as the reference group. A conventional alpha of 0.05 and two-tailed level of significance was used. All analyses were conducted using SAS version 9.2 (SAS Institute Inc., Cary, NC, USA).

\section{Results}

\section{Patient disposition}

Of the 6,818 patients who were contacted, 496 were excluded because they no longer met the study inclusion criteria (Figure 1). Of the remaining 6,322 patients, 1,239 gave verbal consent to participate and 5,083 patients refused. The cooperation rate (the rate of participation agreement among patients who met the inclusion criteria) was $19.6 \%$.

Patients who agreed to participate $(n=1,239)$ were $8.2 \%$ more likely to be female $(P<0.01)$, nearly 1 year younger $(P=0.01)$, and $13.4 \%$ more likely to belong to health plans in the Midwest and Southern regions of the US $(P<0.01)$ than those who refused to participate.

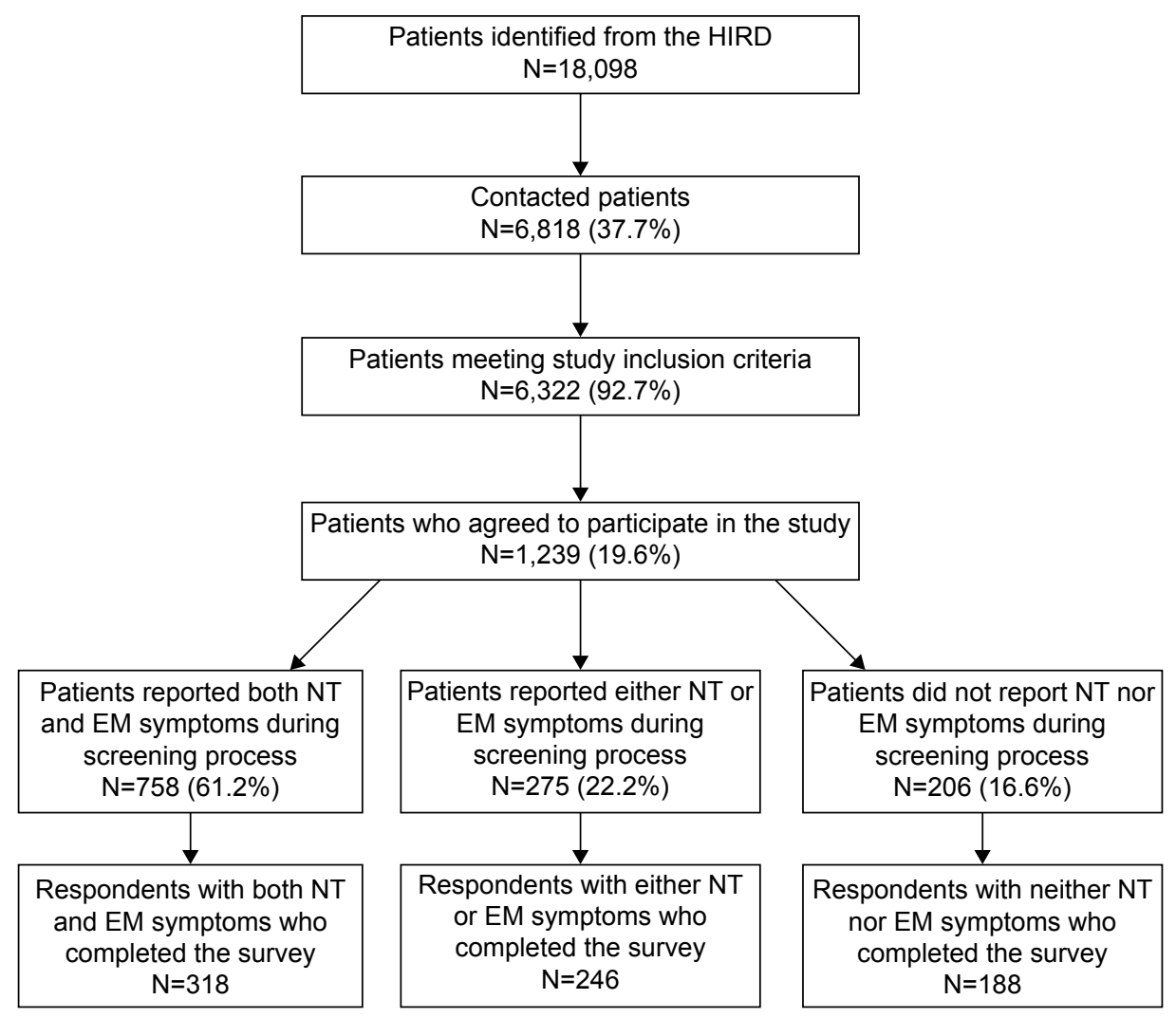

Figure I Flow chart of survey respondents.

Abbreviations: EM, early morning; HIRD, HealthCore Integrated Research Database; NT, nighttime. 


\section{Presence of symptoms}

NT and EM symptoms were common among consenting respondents $(\mathrm{n}=1,239)$, with $758(61.2 \%)$ patients reporting having both NT and EM symptoms on at least three nights and three mornings during the week prior to the survey. A total of 216 (17.4\%) experienced only EM symptoms and 59 (4.8\%) experienced only NT symptoms, meaning that the remaining 206 (16.6\%) patients did not report experiencing NT or EM symptoms on more than three nights or three mornings during the prior week.

\section{Demographic characteristics}

Of the 1,239 consenting respondents, 752 respondents completed the survey (Figure 1). The mean (standard deviation) age was 60.2 (8.0) years, and the average duration of COPD was 6.5 (6.3) years (Table 1). The majority of respondents were female $(60.5 \%)$, white $(91.6 \%)$, with at least some college education $(58.1 \%)$, current or former smokers $(87.1 \%)$, and overweight or obese (69.7\%).

\section{Pattern and impact of NT symptoms}

Respondents who reported having NT symptoms in the week prior to the survey $(n=376)$ reported that, on average, they had experienced these symptoms for at least 5 years, and $73.1 \%$ experienced at least three symptoms over the past week (Table 2). The most frequently reported symptoms were coughing (72.9\%) followed by wheezing $(69.2 \%)$ and shortness of breath $(61.4 \%)$. Half of the respondents perceived their NT symptoms as moderate to very severe. Moreover, respondents reported that these symptoms affected their NT sleep, with $25.3 \%$ reporting difficulty falling asleep, $77.7 \%$ reporting slight to extreme sleep disturbances, and $34.4 \%$ reporting they were awakened at least once per night. Consequently, $59.1 \%$ of patients reported feeling anxious (slightly to extremely) due to their NT symptoms, and $25.3 \%$ used rescue medications on an average of 4.0 (standard deviation 2.3) nights over the past week.

\section{Pattern and impact of EM symptoms}

Similarly, respondents with EM symptoms $(n=506)$ during the week prior to the survey also indicated that they had, on average, experienced EM symptoms for the previous 5 years, and $83 \%$ experienced at least three symptoms over the past week (Table 3). While cough (74.5\%) was also the most frequently reported symptom in the morning, shortness of breath (73.9\%) and bringing up phlegm or mucus (69.6\%) were the next most common. More than half of respondents considered their EM symptoms to be moderate to very severe, which is slightly more than the reported severity of NT symptoms. Like NT symptoms, the impact of EM symptoms was observed, with $60.4 \%$ of respondents reporting limiting their morning activity due to EM symptoms and $27.8 \%$ having trouble concentrating in the morning. Also, $54.3 \%$ of respondents reported feeling anxious (slightly to extremely) due to their EM symptoms. Rescue medication use was also higher among respondents in the morning, with $43.4 \%$ of those with EM symptoms having used rescue medications on an average of 5.1 (standard deviation 2.4) mornings during the prior week.

\section{Factors associated with symptoms}

Multivariate analyses showed that, compared to patients without symptoms, those with both NT and EM symptoms were more likely to be current smokers (odds ratio $[\mathrm{OR}]=2.61 ; 95 \%$ confidence interval $[\mathrm{CI}], 1.18-5.78)$, have used oxygen in the past week (OR=2.2; 95\% CI, 1.02-4.71), experienced dyspnea as measured by mMRC dyspnea scale $(\mathrm{OR}=2.73$; 95\% CI, 1.56-4.76), have poorer health status as measured by the COPD Assessment Test (OR=8.03; 95\% CI, 4.33-14.89), demonstrate low ( $\mathrm{OR}=2.58$; 95\% CI, 1.35-4.93) or moderate $(\mathrm{OR}=2.04 ; 95 \% \mathrm{CI}, 1.13-3.76)$ adherence to COPD medications in the past year, and have experienced an exacerbation in the past year (OR=2.06; 95\% CI, 1.08-3.9). In contrast, only worse health status $(\mathrm{OR}=2.78 ; 95 \% \mathrm{CI}$, 1.70-4.54) was a significant factor when comparing patients with either NT or EM symptoms versus those without any symptoms (Figure 2).

\section{Discussion}

Previous studies have shown that many patients with COPD experience symptoms in the morning and/or during the night, ${ }^{9-11}$ which has highlighted the importance of investigating the occurrence of these symptoms and their association with measures of COPD burden for effective COPD management. Findings from this study indicate that symptoms during the NT and in the morning are common among COPD patients in the US. In addition, the presence of these symptoms has a substantial impact on patients' health-related quality of life and interferes with patients' lives through many factors, including worse sleep quality, limited morning activities, and anxiety.

Consistent with previous studies, ${ }^{19-22}$ the majority of the respondents included in this study were current or former smokers. Being a current smoker, a well-known risk factor for COPD, was found to be independently associated with both NT and EM symptoms, suggesting that COPD patients who 
Table I Demographic and clinical characteristics of survey respondents

\begin{tabular}{|c|c|c|c|c|c|}
\hline & $\begin{array}{l}\text { Total } \\
\text { respondents } \\
\mathbf{N}=\mathbf{7 5 2}\end{array}$ & $\begin{array}{l}\text { Both } N T \text { and } \\
\text { EM symptoms } \\
n=3 \text { I } 8\end{array}$ & $\begin{array}{l}\text { Either } N T \\
\text { or EM symptoms } \\
n=246\end{array}$ & $\begin{array}{l}\text { Neither } \mathrm{NT} \\
\text { nor EM symptoms } \\
\mathrm{n}=188\end{array}$ & $P$-value ${ }^{a}$ \\
\hline Age (years), mean (SD) & $60.2(8.0)$ & $58.6(7.8)$ & $61.0(8.1)$ & $62.0(7.8)$ & $<0.01$ \\
\hline Female, \% & 60.5 & 57.6 & 63.8 & 61.2 & 0.31 \\
\hline White/Caucasian, \% & 91.6 & 92.7 & 91.0 & 90.4 & 0.61 \\
\hline Education status, \% & & & & & 0.05 \\
\hline High school or less & 41.9 & 46.8 & 37.1 & 39.9 & \\
\hline Some college and above & 58.1 & 53.2 & 62.9 & 60.1 & \\
\hline Household income, \% (US\$) & & & & & 0.01 \\
\hline Less than $\$ 25,000$ & 13.3 & 17.3 & 8.8 & 12.1 & \\
\hline$\$ 25,000$ to $\$ 74,999$ & 60.1 & 61.0 & 61.0 & 57.2 & \\
\hline$\$ 75,000$ and over & 26.7 & 21.7 & 30.3 & 30.6 & \\
\hline Employment status, \% & & & & & 0.12 \\
\hline Full-time & 47.5 & 46.5 & 48.0 & 48.7 & \\
\hline Part-time & 10.7 & 7.9 & 11.4 & 14.4 & \\
\hline Not working & 41.8 & 45.6 & 40.7 & 36.9 & \\
\hline $\begin{array}{l}\text { Age at COPD diagnosis (years), } \\
\text { mean } \pm S D\end{array}$ & $53.5 \pm 9.2$ & $51.5 \pm 9.1$ & $54.7 \pm 8.7$ & $55.5 \pm 9.4$ & $<0.01$ \\
\hline COPD duration (years), ${ }^{\mathrm{b}}$ mean \pm SD & $6.5 \pm 6.3$ & $7.1 \pm 6.9$ & $6.0 \pm 5.5$ & $6.2 \pm 6.0$ & 0.11 \\
\hline Smoking status, \% & & & & & $<0.01$ \\
\hline Current smoker & 28.9 & 38.1 & 24.0 & 19.9 & \\
\hline Former smoker & 58.1 & 49.1 & 64.2 & 65.6 & \\
\hline Never smoked & 12.9 & 12.9 & 11.8 & 14.5 & \\
\hline Overweight/obese, ${ }^{c} \%$ & 69.7 & 72.4 & 66.7 & 69.2 & 0.33 \\
\hline Oxygen use in the past week, $\%$ & 15.8 & 20.4 & 16.3 & 7.5 & $<0.01$ \\
\hline Sleep medication use in the past week, \% & 33.4 & 39.0 & 32.9 & 24.5 & $<0.01$ \\
\hline Oral steroid use in the past week, \% & 29.9 & 32.1 & 25.6 & 31.9 & 0.20 \\
\hline COPD exacerbation in the past year, $\%$ & 21.5 & 29.3 & 18.7 & 12.2 & $<0.01$ \\
\hline CAT score categories, $\%$ & & & & & $<0.01$ \\
\hline Low $(<10)$ & 26.4 & 6.6 & 27.9 & 57.8 & \\
\hline Medium (I0-20) & 43.1 & 39.2 & 54.1 & 35.3 & \\
\hline High $(2 \mathrm{I}-30)$ & 24.5 & 39.9 & 18.0 & 7.0 & \\
\hline Very high $(3 \mid-40)$ & 6.0 & 14.2 & 0.0 & 0.0 & \\
\hline mMRC dyspnea score categories, ${ }^{\text {d } \% ~}$ & & & & & $<0.01$ \\
\hline 0 & 28.3 & 13.9 & 32.4 & 48.1 & \\
\hline $\mathrm{I}-4$ & 71.7 & 86.1 & 67.6 & 51.9 & \\
\hline MMAS-8 adherence level, e \% & & & & & $<0.01$ \\
\hline Medication nonusers & 14.5 & 10.1 & 12.6 & 24.5 & \\
\hline Low adherence $(0-5)$ & 23.3 & 30.9 & 19.9 & 14.9 & \\
\hline Moderate adherence (6-7) & 31.2 & 35.3 & 31.3 & 23.9 & \\
\hline High adherence (8) & 31.0 & 23.7 & 36.2 & 36.7 & \\
\hline
\end{tabular}

Notes: analysis of variance was used for continuous variables whereas chi-square/Fisher's exact test was used for categorical variables. ${ }^{\text {bDuration }}$ of COPD was calculated using age at the survey minus age at COPD diagnosis. 'Overweight/obese was defined as body mass index $\geq 25 \mathrm{~kg} / \mathrm{m}^{2}$, which was calculated as weight in pounds divided by square of height in inches multiplied by 703 . ${ }^{~}$ Patients were considered as having dyspnea symptoms if $\mathrm{mMRC}$ dyspnea scale responses $=\mathrm{I}-4$ and were considered as being without dyspnea symptoms if $\mathrm{mMRC}$ scale response $=0$. ePatients were categorized into four levels: I) patients who did not take any COPD-related medications; 2 ) patients who took COPD-related medications and had a MMAS-8 score $=0-5$ (low adherence); 3 ) patients who took COPD-related medications and had a MMAS score $=6-7$ (moderate adherence); and 4) patients who took COPD-related medications and had a MMAS score $=8$ (high adherence).

Abbreviations: CAT, COPD Assessment Test; COPD, chronic obstructive pulmonary disease; EM, early morning; MMAS-8, Morisky Medication Adherence Scale; mMRC, modified Medical Research Council; NT, nighttime; SD, standard deviation.

continue to smoke may experience worse symptoms at night and in the morning. This study further showed that, compared with respondents without NT/EM symptoms, patients with both symptoms were more likely to report home oxygen use during the day or at night. Evidence has shown that oxygen therapy can alleviate hypoxemia and reduce dyspnea symptoms for patients with COPD; ${ }^{23}$ however, clinical trials and studies on the efficacy or effectiveness of long-term oxygen therapy are needed, especially for severe COPD patients. ${ }^{24}$ A greater proportion of respondents with symptoms reported 
Table 2 Type, severity, and impact of NT symptoms

\begin{tabular}{|c|c|c|}
\hline \multirow[b]{2}{*}{ Types of NT symptoms over past week } & \multicolumn{2}{|c|}{ Respondents with NT symptoms $\mathbf{N}=376$} \\
\hline & & \\
\hline Short of breath or breathless, n, \% & 231 & $61.4 \%$ \\
\hline Nights with shortness of breath or breathlessness, mean \pm SD & 4.5 & \pm 2.0 \\
\hline Coughing, n, \% & 274 & $72.9 \%$ \\
\hline Nights with coughing, mean \pm SD & 4.9 & \pm 2.1 \\
\hline Bringing up phlegm or mucus, $\mathrm{n}, \%$ & 229 & $60.9 \%$ \\
\hline Nights with bringing up phlegm or mucus, mean \pm SD & 4.8 & \pm 2.1 \\
\hline Tightness in chest, n, \% & 164 & $43.6 \%$ \\
\hline Nights with tightness in chest, mean \pm SD & 4.2 & \pm 2.2 \\
\hline Chest congestion, n, \% & 183 & $48.7 \%$ \\
\hline Nights with chest congestion, mean \pm SD & 4.9 & \pm 2.0 \\
\hline Wheezing, n, \% & 260 & $69.2 \%$ \\
\hline Nights with wheezing, mean \pm SD & 5.0 & \pm 2.1 \\
\hline \multicolumn{3}{|l|}{ Severity of NT symptoms over past week, n, \% } \\
\hline Did not experience any symptoms & 9 & $2.4 \%$ \\
\hline Mild & 179 & $47.6 \%$ \\
\hline Moderate & 160 & $42.6 \%$ \\
\hline Severe & 23 & $6.1 \%$ \\
\hline Very severe & 5 & $1.3 \%$ \\
\hline \multicolumn{3}{|l|}{ Impact of NT symptoms over past week } \\
\hline Difficult to fall asleep, $\mathrm{n}, \%$ & 190 & $25.3 \%$ \\
\hline Nights on which it felt difficult to fall asleep, mean \pm SD & 3.8 & \pm 2.1 \\
\hline \multicolumn{3}{|l|}{ Sleep disturbed, $n, \%$} \\
\hline Not at all & 81 & $22.1 \%$ \\
\hline Slightly & 122 & $33.2 \%$ \\
\hline Moderately & 130 & $35.4 \%$ \\
\hline Severely & 21 & $5.7 \%$ \\
\hline Extremely & 12 & $3.3 \%$ \\
\hline Refused to answer & 1 & $0.3 \%$ \\
\hline Woke up at least once, n, \% & 259 & $34.4 \%$ \\
\hline Nights woke up, mean \pm SD & 3.8 & \pm 2.1 \\
\hline Felt rested in morning, $\mathrm{n}, \%$ & 230 & $30.6 \%$ \\
\hline Mornings felt rested, mean \pm SD & 4.0 & \pm 2.0 \\
\hline \multicolumn{3}{|l|}{ Anxious, $n, \%$} \\
\hline Not at all anxious & 150 & $40.9 \%$ \\
\hline Slightly anxious & 105 & $28.6 \%$ \\
\hline Moderately anxious & 67 & $18.3 \%$ \\
\hline Considerably anxious & 29 & $7.9 \%$ \\
\hline Extremely anxious & 16 & $4.4 \%$ \\
\hline Used rescue medications, $n, \%$ & 190 & $25.3 \%$ \\
\hline
\end{tabular}

Abbreviations: NT, nighttime; SD, standard deviation.

using sleep medications (including prescriptions, over-thecounter medications, and herbal remedies) during the week before the survey, although it was not shown to be a significant factor associated with NT/EM symptoms after adjusting for other covariates.

Existing literature has shown that sleep disturbance among patients with COPD can have a number of negative impacts. One study conducted in Europe found that $26.5 \%$ of patients reported their sleep quality was affected by frequent waking during the night and difficulty falling asleep, ${ }^{10}$ which is similar to the $25.3 \%$ of respondents in this study who reported having difficulty falling asleep due to symptoms at NT. Our results are also consistent with the qualitative study conducted by Shackell et $\mathrm{al}^{25}$ showing that patients with COPD experience nocturnal fear and anxiety; in addition, one-fourth of respondents reported the use of rescue medications (eg, albuterol) between their bedtime and the time when they woke up to start a day.

While sleep disturbance is worse with increased symptoms at night, sleep disturbance itself is multifaceted and can be caused by a number of factors, including suboptimal evening routines, which may disrupt normal sleeping patterns. ${ }^{25}$ 
Table 3 Type, severity, and impact of EM symptoms

\begin{tabular}{|c|c|c|}
\hline \multirow[b]{2}{*}{ Types of EM symptoms over past week } & \multicolumn{2}{|c|}{ Respondents with EM symptoms $\mathrm{N}=506$} \\
\hline & & \\
\hline Short of breath or breathless, $n, \%$ & 374 & $73.4 \%$ \\
\hline Nights with shortness of breath or breathlessness, mean \pm SD & 5.0 & \pm 2.1 \\
\hline Coughing, n, \% & 377 & $74.5 \%$ \\
\hline Nights with coughing, mean \pm SD & 5.6 & \pm 1.9 \\
\hline Bringing up phlegm or mucus, $\mathrm{n}, \%$ & 352 & $69.6 \%$ \\
\hline Nights with bringing up phlegm or mucus, mean \pm SD & 5.4 & \pm 2.0 \\
\hline Tightness in chest, $n, \%$ & 207 & $40.9 \%$ \\
\hline Nights with tightness in chest, mean \pm SD & 4.3 & \pm 2.2 \\
\hline Chest congestion, $\mathrm{n}, \%$ & 233 & $46.1 \%$ \\
\hline Nights with chest congestion, mean \pm SD & 4.9 & \pm 2.1 \\
\hline Wheezing, n, \% & 300 & $59.3 \%$ \\
\hline Nights with wheezing, mean \pm SD & 5.0 & \pm 2.2 \\
\hline \multicolumn{3}{|l|}{ Severity of EM symptoms over past week, n, \% } \\
\hline Mild & 222 & $43.9 \%$ \\
\hline Moderate & 234 & $46.3 \%$ \\
\hline Severe & 45 & $8.9 \%$ \\
\hline Very severe & 4 & $0.8 \%$ \\
\hline \multicolumn{3}{|l|}{ Impact of EM symptoms over past week } \\
\hline \multicolumn{3}{|l|}{ Activity limited, n, \% } \\
\hline Not at all & 200 & $39.6 \%$ \\
\hline Slightly & 113 & $22.4 \%$ \\
\hline Moderately & 96 & $19.0 \%$ \\
\hline Severely & 62 & $12.3 \%$ \\
\hline Extremely & 34 & $6.7 \%$ \\
\hline Trouble concentrating, $\mathrm{n}, \%$ & 209 & $27.8 \%$ \\
\hline Mornings trouble concentrating, mean \pm SD & 4.3 & \pm 2.0 \\
\hline \multicolumn{3}{|l|}{ Anxious, $n, \%$} \\
\hline Not at all & 229 & $45.4 \%$ \\
\hline Slightly & 145 & $28.7 \%$ \\
\hline Moderately & 74 & $14.7 \%$ \\
\hline Considerably & 41 & $8.1 \%$ \\
\hline Extremely & 14 & $2.8 \%$ \\
\hline Refused to answer & 2 & $0.4 \%$ \\
\hline Used rescue medications, $n, \%$ & 326 & $43.4 \%$ \\
\hline
\end{tabular}

Abbreviations: EM, early morning; SD, standard deviation.

This is important because while it may be difficult to treat all facets of sleep disruption, the reduction of COPD symptoms during the evening hours may be amenable to treatment with maintenance medications. In fact, evidence exists that some medications already available to patients with COPD may help reduce NT symptoms of COPD. ${ }^{12,26}$

The study results are also consistent with the small body of literature around EM symptoms of COPD. In an international study conducted within five European countries, morning was reported to be the worst time of day among COPD patients; $9.5 \%$ of patients required assistance with their morning activity routines, and of these patients, $67.5 \%$ felt worried that they were a burden to others. ${ }^{10}$ Similarly, an internet survey study found that $74 \%$ of patients with COPD reported that their morning activities took longer to complete than usual, with $21 \%$ of patients requiring help to perform their morning routine. ${ }^{11}$ Our results confirm those findings, with more than half of respondents reporting morning activity limitation and anxiety, and nearly half of respondents having used rescue medications on more than 5 days in the week prior to the survey. Most recently, a multinational study of patients with EM symptoms reported that those with symptoms had worse quality of life, more exacerbations, and more work days off per year. ${ }^{27}$ The results support previous findings that breathlessness is highly prevalent at night and in the $\mathrm{EM} ;{ }^{10,11,28}$ however, cough was the most frequently reported EM symptom (74.5\%) and NT symptom (72.9\%). Partridge et $\mathrm{al}^{11}$ found that COPD symptoms significantly impact sleep quality and morning routine, which can, in turn, negatively affect patients' health status. ${ }^{11,29}$ Our findings showed that experiencing either NT 

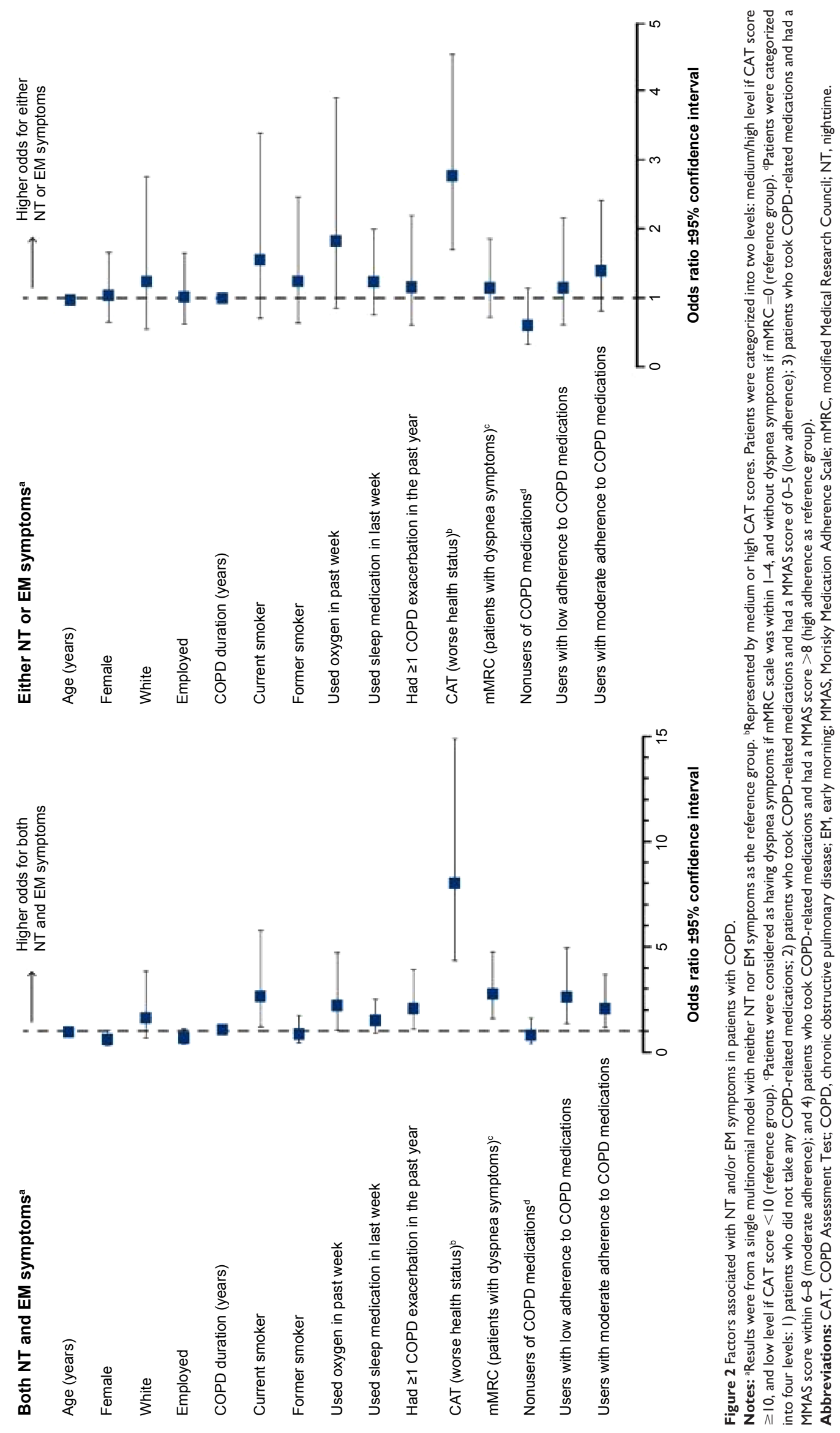
or EM symptoms was significantly associated with poorer health status, even after controlling for sociodemographic and clinical characteristics. Furthermore, experiencing both NT and EM symptoms had a greater overall impact than having only one of the two types of symptoms. That is, the presence of both NT and EM symptoms was not only significantly associated with poorer health status but also with the occurrence of previous exacerbations, dyspnea, and poor medication adherence.

The findings from this study should be interpreted in light of certain limitations. Patients were identified from medical and pharmacy claims in a large US administrative claims database, which may contain diagnostic or treatment coding errors. Although patients in this study confirmed their COPD diagnosis by answering self-reported screening questions, they were not asked whether or not they had asthma. It is possible that patients with ICD-9-CM codes for both asthma and COPD were first evaluated and diagnosed with asthma, and later diagnosed with only COPD. As the study respondents were identified from a large US administrative claims database, only individuals and/or their dependents with employer-provided health insurance were included. It is possible that the results from this study may not generalize to other populations consisting of uninsured individuals, Medicaid or Medicare recipients, or patients in countries other than the US with different health care systems. Additionally, the results were based on respondents' self-report and could not be independently verified through clinical documentation; thus, their accuracy may be subject to self-report and recall biases. Furthermore, some differences in terms of age, sex, and health plan region were observed between respondents and nonrespondents, but the differences were relatively minimal, with more respondents being female ( $6 \%)$, older ( 1.5 years), and having health plans in the Midwest region (9\%). Lastly, this study did not collect objective ventilatory function data. Future studies should endeavor to correlate this data with NT and EM symptoms to further elucidate the impact of these symptoms.

\section{Conclusion}

In summary, most COPD patients with self-reported NT and EM symptoms consider their symptoms to be moderate to severe and perceive that symptoms affect their sleep, morning activities, and anxiety levels. Improvements in disease management approaches may decrease the burden associated with these symptoms, which could have significant humanistic impacts on patients, employers, and the health care system. Further study is needed to better understand the relationship of NT and EM symptoms with health-related quality of life, risk for exacerbations, as well as the effect of interventions on relieving these symptoms.

\section{Acknowledgments}

This study was supported by a contract from Forest Laboratories LLC, an affiliate of Actavis plc, New York, NY, USA to HealthCore, Inc, Wilmington, DE, USA. Editorial assistance, provided by Prescott Medical Communications Group, Chicago, IL, USA, was funded by Forest Research Institute, Inc. The authors alone are responsible for the content and writing of this paper. Use of the MMAS is protected by US copyright laws. Permission for use is required. Alicense agreement was obtained from Donald E Morisky, ScD, ScM, MSPH, Professor, Department of Community Health Sciences, UCLA School of Public Health, 650 Charles E Young Drive South, Los Angeles, CA90095-1772, USA.

\section{Author contributions}

All authors contributed to the study concept and design. QC performed data analysis, with assistance from JJS. All authors participated in interpretation of the data, development of the manuscript, and approved this manuscript for submission.

\section{Disclosure}

JJS, QC, and HT are employees of HealthCore Inc, a subsidiary of Anthem Inc., whose activities in the study were funded by Forest Research Institute, Inc., an affiliate of Actavis plc. MM was an employee of Forest Research Institute, Inc. at the time of the study and had stock/stock options. MM is currently employed by Novo Nordisk. JAD has received consulting fees from Forest Research Institute, Inc., Merck, and Boehringer Ingelheim and research grants from Pfizer and Amgen. SDS reports no conflicts of interest in this work.

\section{References}

1. Anderson B, Conner K, Dunn C, Kerestes G, Lim K, Myers C, Olson J, Raikar S, Schultz H, Setterlund L. Institute for Clinical Systems Improvement. Diagnosis and Management of Chronic Obstructive Pulmonary Disease (COPD). Updated March 2013:7 [cited June 27, 2013]. Available from: https://www.icsi.org/_asset/yw83gh/COPD.pdf. Accessed February 4, 2015.

2. Punturieri A, Croxton TL, Weinmann GG, Kiley JP. Chronic obstructive pulmonary disease: a view from the NHLBI. Am J Respir Crit Care Med. 2008;178(5):441-443.

3. Mannino DM, Homa DM, Akinbami LJ, Ford ES, Redd SC. Chronic obstructive pulmonary disease surveillance - United States, 1971-2000. Respir Care. 2002;47(10):1184-1199.

4. United States Department of Health and Human Services; National Institutes of Health; National Heart Lung and Blood Institute. Morbidity and Mortality: 2012 Chartbook on Cardiovascular, Lung and Blood Diseases. Bethesda: National Heart, Lung, and Blood Institute; 2012 [cited June 27, 2013]. Available from: http://www.nhlbi.nih.gov/ research/reports/2012-mortality-chart-book. Accessed June 27, 2013 
5. Chronic Obstructive Pulmonary Disease (COPD) Fact Sheet [webpage on the Internet]. Chicago: American Lung Association; 2013 [cited October 22, 2013] Available from: http://www.lung.org/lungdisease/copd/resources/facts-figures/COPD-Fact-Sheet.html\#note_12. Accessed October 22, 2013.

6. Murphy SL, Xu J, Kochanek KD. Deaths: final data for 2010. Natl Vital Stat Rep. 2013;61(4):1-117.

7. Lozano R, Naghavi M, Foreman K, et al. Global and regional mortality from 235 causes of death for 20 age groups in 1990 and 2010: a systematic analysis for the Global Burden of Disease Study 2010. Lancet. 2012;380(9859):2095-2128.

8. Vestbo J, Hurd SS, Agustí AG, et al. Global strategy for the diagnosis, management, and prevention of chronic obstructive pulmonary disease: GOLD executive summary. Am J Respir Crit Care Med. 2013;187(4):347-365.

9. Agusti A, Hedner J, Marin JM, Barbé F, Cazzola M, Rennard S. Nighttime symptoms: a forgotten dimension of COPD. Eur Respir Rev. 2011;20(121):183-194.

10. Kessler R, Partridge MR, Miravitlles M, et al. Symptom variability in patients with severe COPD: a pan-European cross-sectional study. Eur Respir J. 2011;37(2):264-272.

11. Partridge MR, Karlsson N, Small IR. Patient insight into the impact of chronic obstructive pulmonary disease in the morning: an internet survey. Curr Med Res Opin. 2009;25(8):2043-2048.

12. Lopez-Campos JL, Calero C, Quintana-Gallego E. Symptom variability in COPD: a narrative review. Int J Chron Obstruct Pulmon Dis. 2013;8:231-238.

13. Kuyucu T, Güçlü SZ, Saylan B, et al. A cross-sectional observational study to investigate daily symptom variability, effects of symptom on morning activities and therapeutic expectations of patients and physicians in COPD-SUNRISE study. Tuberk Toraks. 2011;59(4):328-339.

14. Global Initiaive for Chronic Obstructive Lung Disease [webpage on Internet]. GOLD 2011 Summary. Available from: http://www.goldcopd. org/guidelines-gold-summary-2011.html. Accessed January 15, 2015.

15. Bestall JC, Paul EA, Garrod R, Garnham R, Jones PW, Wedzicha JA. Usefulness of the Medical Research Council (MRC) dyspnoea scale as a measure of disability in patients with chronic obstructive pulmonary disease. Thorax. 1999;54(7):581-586.

16. Mahler DA, Ward J, Waterman LA, McCusker C, Zuwallack R, Baird JC. Patient-reported dyspnea in COPD reliability and association with stage of disease. Chest. 2009;136(6):1473-1479.
17. Jones PW, Harding G, Berry P, Wiklund I, Chen WH, Kline Leidy N. Development and first validation of the COPD Assessment Test. Eur Respir J. 2009;34(3):648-654.

18. Morisky DE, Ang A, Krousel-Wood M, Ward HJ. Predictive validity of a medication adherence measure in an outpatient setting. $J$ Clin Hypertens (Greenwich). 2008;10(5):348-354.

19. Centers for Disease Control and Prevention (CDC). Chronic obstructive pulmonary disease among adults - United States, 2011. MMWR Morb Mortal Wkly Rep. 2012;61(46):938-943.

20. DiBonaventura Md, Paulose-Ram R, Su J, et al. The impact of COPD on quality of life, productivity loss, and resource use among the elderly United States workforce. COPD. 2012;9(1):46-57.

21. DiBonaventura Md, Paulose-Ram R, Su J, et al. The burden of chronic obstructive pulmonary disease among employed adults. Int $J$ Chron Obstruct Pulmon Dis. 2012;7:211-219.

22. Cecere LM, Littman AJ, Slatore CG, et al. Obesity and COPD: associated symptoms, health-related quality of life, and medication use. COPD. 2011;8(4):275-284.

23. Kim V, Benditt JO, Wise RA, Sharafkhaneh A. Oxygen therapy in chronic obstructive pulmonary disease. Proc Am Thorac Soc. 2008;5(4):513-518.

24. Croxton TL, Bailey WC. Long-term oxygen treatment in chronic obstructive pulmonary disease: recommendations for future research: an NHLBI workshop report. Am J Respir Crit Care Med. 2006;174(4):373-378.

25. Shackell BS, Jones RC, Harding G, Pearse S, Campbell J. 'Am I going to see the next morning?' A qualitative study of patients' perspectives of sleep in COPD. Prim Care Respir J. 2007;16(6):378-383.

26. Welte T, Miravitlles M, Hernandez P, et al. Efficacy and tolerability of budesonide/formoterol added to tiotropium in patients with chronic obstructive pulmonary disease. Am J Respir Crit Care Med. 2009;180(8):741-750.

27. Roche N, Small M, Broomfield S, Higgins V, Pollard R. Real world COPD: association of morning symptoms with clinical and patient reported outcomes. COPD. 2013;10(6):679-686.

28. Parish JM. Sleep-related problems in common medical conditions. Chest. 2009;135(2):563-572.

29. Nunes DM, Mota RM, de Pontes Neto OL, Pereira ED, de Bruin VM, de Bruin PF. Impaired sleep reduces quality of life in chronic obstructive pulmonary disease. Lung. 2009;187(3):159-163.
International Journal of COPD

\section{Publish your work in this journal}

The International Journal of COPD is an international, peer-reviewed journal of therapeutics and pharmacology focusing on concise rapid reporting of clinical studies and reviews in COPD. Special focus is given to the pathophysiological processes underlying the disease, intervention programs, patient focused education, and self management protocols.

\section{Dovepress}

This journal is indexed on PubMed Central, MedLine and CAS. The manuscript management system is completely online and includes a very quick and fair peer-review system, which is all easy to use. Visit http://www.dovepress.com/testimonials.php to read real quotes from published authors. 